\title{
Periodontal Disease and Gingival Innate Immunity - Who Has the Upper Hand?
}

\author{
Whasun Oh Chung and Jonathan Y. An \\ University of Washington, Seattle, WA
}

USA

\section{Introduction}

Dental plaque is a complex microbial biofilm that forms at high cell density in the oral cavity by the successive accumulation of hundreds of different species of bacteria. Both host immune and bacterial factors are involved in the progression from healthy to diseased state in plaque biofilm, and in the oral cavity, gingival epithelial cells (GECs) are one of the first host cell types that encounter colonizing bacteria. As a consequence, GECs respond to the presence of bacteria through an elaborate signaling network, producing antimicrobial peptides (AMPs) and cytokines, leading to host innate immune responses. Periodontal disease is a consequence of the imbalance between the pathogenic potential of the biofilm and host immune defense properties, resulting in an inflammatory reaction of the periodontium. As a part of host defense mechanism, GECs secrete specific endogenous serine protease inhibitors to prevent tissue damage from excessive proteolytic enzyme activity due to inflammation. Recent studies showed GECs induced different serine protease inhibitors in the presence of non-pathogenic bacteria, but these protease inhibitors were attenuated by periopathogens, whose main virulence factors are proteases. Furthermore, periodontal patients with periopathogens present in their plaque exhibited significantly lower protease inhibitors in gingival crevicular fluid in comparison to healthy controls. The degradation of protease inhibitors by periopathogens may result in decreased host protective capacity, and the balance between cellular protease inhibitors and their degradation by periodontal pathogens may be an important factor in susceptibility to breakdown from chronic infection. In addition to bacterial infection, genetic and environmental factors contribute to occurrence and progression of periodontal disease. Recent studies suggest that the manifestation and severity of periodontal disease may be influenced by epigenetic factors. Many patients with the same clinical symptoms respond differently to the same therapy, suggesting the interindividual variability observed as a clinical outcome of the disease is influenced by genetic as well as epigenetic factors.

In this chapter, we will closely examine the mechanisms gingival epithelia utilize in inducing AMPs in response to bacterial presence and assess future therapeutic potential of AMPs. We will also focus on the impact the balance between the proteases and protease inhibitors has on oral health and how epigenetic modifications brought on by exposure to periodontal pathogens affect the progression of periodontal disease. 


\section{Microbial biofilm and innate immune responses of gingiva}

Dental plaque is a complex microbial biofilm that forms at high cell density on tooth surfaces in the oral cavity by the successive accumulation of over 500 different species of bacteria (Kolenbrander, Andersen et al. 2002; Rickard, Gilbert et al. 2003). The early colonizers of the tooth surface are mainly non-pathogens comprised of Gram-positive facultative organisms, including Streptococcus gordonii, Streptococcus sanguis and Streptococcus oralis. These initial colonizers adhere to salivary pellicle on teeth, leading to successive colonization of Gram-negative anaerobes such as Fusobacterium nucleatum and finally to pathogens such as Porphyromonas gingivalis. The formation of plaque has been linked to the human oral diseases, caries and periodontitis (Socransky, Smith et al. 2002; Socransky and Haffajee 2005), and both host immune and bacterial factors are involved in the progression from healthy to diseased state in plaque biofilm.

Periodontitis is one of most common inflammatory diseases and can be of inflammatory, traumatic, metabolic, developmental and/or genetic origin. In most cases, periodontal disease results in an inflammatory reaction of the periodontium to pathogenic microorganisms. Among various species of microorganisms making up oral biofilm that accumulates on the tooth surface adjacent to the gingiva, Gram-negative anaerobic bacteria P. gingivalis, Tannerella forsythia and Treponema denticola in particular have been strongly associated with periodontal disease (Socransky, Haffajee et al. 1998; Armitage 1999; Socransky and Haffajee 2003). Bacteria first form a supra-gingival biofilm attached to the tooth surface, and once they have passed the junctional epithelium, bacteria may enter the gingival crevice to form sub-gingival biofilm, which provides an optimal environment for anaerobic bacteria to colonize and reproduce (Socransky and Haffajee 2003). The number of Gram-negative anaerobic bacteria increases during development and maturation of the dental biofilm. Both host immune and bacterial factors are involved in the progression from healthy to diseased state in plaque biofilm, thus periodontal disease is the result of the imbalance between the pathogenic potential of the biofilm and host immune defense properties. In addition, genetic and/or environmental factors, such as smoking, contribute to occurrence and progression of periodontal disease (Michalowicz, Aeppli et al. 1991; Michalowicz, Diehl et al. 2000; Kinane and Hart 2003; Loos, John et al. 2005).

$P$. gingivalis is an aggressive pathogen and considered an etiologic agent of severe adult periodontitis. Colonization of the oral cavity by $P$. gingivalis is facilitated by adherence to various oral surfaces, including epithelial cells, the salivary pellicle that coats tooth surfaces, and other oral bacteria that comprise the plaque biofilm (Socransky and Haffajee 1992). However, $P$. gingivalis is considered a secondary colonizer of plaque and rarely colonizes the tooth surface until initial plaque bacteria, such as $S$. gordonii, establish an appropriate environment. Adhesion between $S$. gordonii and P. gingivalis is mediated by $S$. gordonii cellsurface protein SspB and P. gingivalis minor fimbriae (Chung, Demuth et al. 2000). In the oral cavity, gingival epithelial cells are one of the first host cell types that encounter colonizing bacteria. As a consequence, epithelial cells respond to the presence of bacteria through an elaborate signaling network, producing antimicrobial peptides and cytokines, and at times stimulating apoptotic cell death. This bacterial-host communication takes place via a number of signal transduction pathways, but different bacteria may induce different signals from the host. Conversely, various host immune responses may interfere with the way commensals and pathogens communicate to form biofilm, although this means of defense is poorly understood. 
Periodontal disease is of importance not only in oral health, but also in general health because of its association with an increased risk of preterm births and low birth weight babies (Offenbacher, Katz et al. 1996; Buduneli, Baylas et al. 2005). Thus, it is of importance to understand how oral bacteria alter host innate immune responses and how periodontal disease is affected by protective factors induced by the host.

\section{The role of Antimicrobial Peptides in periodontal health}

\subsection{Antimicrobial Peptides (AMPs)}

In the presence of diverse environment of microbial consortiums, epithelia express several natural antimicrobial peptides (AMPs) which work synergistically with a broad spectrum of activity against both Gram-negative and Gram-positive bacteria, as well as against yeast and some virus to maintain balance between health and disease (Hancock and Chapple 1999; Lehrer and Ganz 2002; Premratanachai, Joly et al. 2004). AMPs are small cationic peptides with molecular weights typically ranging between 3,500 and 6,500 Da (Dale 2002). They adopt amphiphilic topologies, which allows them to interact and selectively disrupt microbial cell membranes (Som, Vemparala et al. 2008). In humans these antimicrobial peptides include defensins and a cathelicidin family member LL-37 in skin and oral mucosa and other epithelia (Hancock and Scott 2000; Lehrer and Ganz 2002; Selsted and Ouellette 2005). The human defensins include the alpha-defensins of intestinal and neutrophil origin, and the beta-defensins of skin and oral mucosa and other epithelia. Alpha-defensins are expressed in neutrophils as part of their non-oxidative antimicrobial mechanisms (Lehrer, Lichtenstein et al. 1993; van Wetering, Sterk et al. 1999). Alphadefensins are also found in Paneth cells in the intestine (Selsted 1992; Ouellette 1999). They are synthesized as precursors that are proteolytically activated and released during inflammation (Rock 1998; Wilson, Ouellette et al. 1999). The human beta-defensins (hBDs) are small, cationic antimicrobial peptides made primarily by epithelial cells and expressed in all human epithelia tested to date (Dale 2002). The beta-defensins are secreted in biological fluids, including urine, bronchial fluids, nasal secretions, saliva and gingival crevicular fluid (Valore, Park et al. 1998; Cole 1999; Sahasrabudhe 2000; Diamond, Kimball et al. 2001). hBDs were first identified in tracheal epithelial cells and subsequently found in many epithelia including kidney and urinary tract, oral mucosa and skin (Diamond, Russell et al. 1996; Zhao, Wang et al. 1996; Krisanaprakornkit, Weinberg et al. 1998; Valore, Park et al. 1998).

The expression of the cathelicidin, LL-37, is found in human tongue, buccal mucosa and saliva following inflammatory stimulation (Frohm Nilsson, Sandstedt et al. 1999; Murakami, Ohtake et al. 2002). It is kept inactive until proteases cleave the conserved proregion (Zanetti, Gennaro et al. 2000). Immunohistochemistry studies found that LL-37, derived from neutrophils, was detected in the junctional epithelium (Dale, Kimball et al. 2001). The defensins and LL-37 are localized in different sites in gingiva, which suggests that they may play different roles in specific sites in which they are expressed (Dale, Kimball et al. 2001). Because these AMPs have synergistic effects, their presence in saliva may provide natural antimicrobial barrier (Tao, Jurevic et al. 2005). Different sites within the oral cavity where various AMPs are predominantly expressed are depicted in Figure 1. 


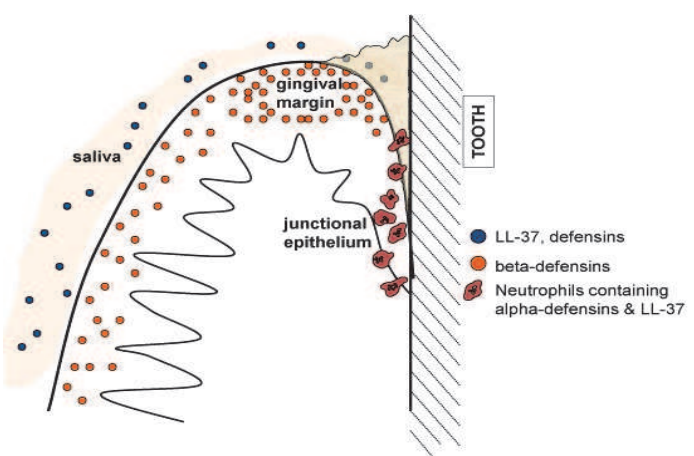

Fig. 1. Various sites in the oral cavity where different AMPs are predominantly expressed. Dale and Fredericks 2005; permission from Horizon Scientific Press

\subsubsection{Alpha-defensins}

Alpha- and beta-defensins are peptides with six disulfide-linked cysteines. Structurally, the difference between the two defensins lies within the length of peptide segments between the six cysteines and pairing of the cysteines (Bals and Wilson 2003). Six different human alphadefensins have been identified so far, including four human neutrophil peptides, HNP1-4, and two others known as human defensins 5 and 6 (HD-5, HD-6) (Ganz, Selsted et al. 1985; Ganz and Lehrer 1994; Cunliffe 2003). Alpha-defensins are arginine-rich and localized in either neutrophil azurophilic granules or Paneth cells, which are the epithelia of the intestinal mucosa. During gingivitis, neutrophils dominate the lesion area, but the relative proportion compared to plasma cells and lymphocytes in neutrophils decreases during the transition to periodontitis (Kinane and Bouchard 2008; Nussbaum and Shapira 2011). Disorders in neutrophil production have been associated with destruction of periodontal tissue and eventual periodontal disease (Crawford, Wilton et al. 2000). Within neutrophils, human alpha-defensins are abundant and work together with the oral epithelium to provide a barrier to microbial colonization, particularly in the junctional epithelium of the tooth surface (Dale and Fredericks 2005). Studies have shown that two periodontal pathogens, $P$. gingivalis and Aggregatibacter actinomycetemcomitans, as well as non-pathogenic commensal bacteria S. gordonii are insensitive to alpha-defensin activity (Miyasaki, Bodeau et al. 1990; Zhong, Yang et al. 1998; Raj, Antonyraj et al. 2000). However, when extra amino acids were added to the N-terminus and C-terminus end of HNP2, an enhanced antibacterial activity against the same bacteria was shown, indicating the structural anatomy is a crucial determinant in this AMP's antibacterial activity (Raj, Antonyraj et al. 2000).

HNP 1-3 are detected in the junctional epithelium and the gingival crevicular fluid (GCF), and GCF from patients with aggressive and chronic periodontitis showed significantly elevated levels of HNP 1-3 compared to healthy patients (McKay, Olson et al. 1999; Dale, Kimball et al. 2001). Interestingly, the increased concentration of both alpha- and betadefensins was correlated in patients with chronic periodontitis with the amount of periodontal pathogens P. gingivalis, T. denticola, and T. forsythia (Puklo, Guentsch et al. 2008). Recently, HNP1 and HNP2 were shown to decrease the response of pro-inflammatory cytokine IL-6, while enhancing antibody response to specific $P$. gingivalis adhesin in mice (Kohlgraf, Ackermann et al. 2010). Thus, alpha-defensins may play a key role as a mediator of innate immunity in gingiva against periopathogenic microbes. 


\subsubsection{Beta-defensins}

Beta-defensins 1 and 2 (hBD-1 and hBD-2) are found in normal, uninflamed gingival tissues as part of the innate host defense mechanism (Krisanaprakornkit, Weinberg et al. 1998; Dale, Kimball et al. 2001). Furthermore, hBD-1 and hBD-2 are localized at the gingival margin where there is the most exposure to oral bacteria of the plaque on the tooth surface, but not in the junctional epithelium. Thus, the junctional epithelium is protected by alpha-defensins and LL-37 released from neutrophils, while the differentiated, stratified epithelia are protected by beta-defensins. Structurally a reduced hBD-1 differs from an oxidized hBD-1, and a reduction in the disulfide bridges of hBD-1 causes the peptide to become a potent AMP against opportunistic pathogen Candida albicans and Lactobacillus species (Schroeder, Wu et al. 2011). A structural modulation of hBD-1, dependent on the environment it exists in the oral cavity, could shield the healthy epithelium against colonization by commensal and periopathogenic bacteria. However, compared to other beta-defensins, hBD-1 only shows a minor effect against oral bacteria, such as $P$. gingivalis, A. actinomycetemcomitans, Prevotella intermedia, and F. nucleatum (Ouhara, Komatsuzawa et al. 2005).

In oral epithelia, the expression of hBD-2 is found in normal, uninflamed gingival tissues and is induced by various bacteria (Krisanaprakornkit, Kimball et al. 2000; Dale, Kimball et al. 2001; Chung and Dale 2004). The expression of hBD-2 after challenge from a commensal bacterium indicates that the normal oral epithelium is already at a heightened state to combat potentially harmful pathogens (Krisanaprakornkit, Kimball et al. 2000; Chung and Dale 2004).

hBD-3 has shown bactericidal activity against a wide range of oral bacteria, including periodontal pathogens A. actinomycetemcomitans and P. gingivalis, and cariogenic bacteria Streptococcus mutans (Maisetta, Batoni et al. 2003). Furthermore, both normal GECs and immortalized human oral epithelial cells showed an increase in hBD-3 levels upon exposure to A. actinomycetemcomitans (Feucht, DeSanti et al. 2003). Similar to HNPs, the peptide has also been detected in the GCF of healthy individuals, and a significant decrease in hBD-3 levels in GCF correlated with the stage of periodontitis, with a negative correlation between hBD-3 levels with the number of periopathogenic bacteria within the same site (Bissell, Joly et al. 2004; Brancatisano, Maisetta et al. 2011).

Studies on the regulation of the induction of beta-defensins reveal different ways gingival epithelia respond to the presence of pathogenic and non-pathogenic bacteria. Our group has reported the induction of hBD-2 by GECs in response to commensal bacteria like $F$. nucleatum and S. gordonii utilized p38 and JNK MAPK pathways, while in response to periopathogenic bacteria like $P$. gingivalis and A. actinomycetemcomitans, GECs utilized the NF- $\mathrm{\kappa B}$ pathway in addition to the aforementioned MAPK (Krisanaprakornkit, Kimball et al. 2002; Chung and Dale 2008). Our group has further reported gingival innate immune response to $P$. gingivalis involves Protease-activated receptor-2 (PAR-2), a G-protein coupled receptor (Chung, Hansen et al. 2004; Dommisch, Chung et al. 2007). A study from another group reported mice given oral doses of $P$. gingivalis showed alveolar bone loss, but in PAR2 deficient mice the amount of bone loss was significantly less, indicating PAR-2 may have a role in the inflammatory response against $P$. gingivalis (Holzhausen, Spolidorio et al. 2006). In addition, a recent study revealed that the expression of hBD-3 in response to another periodontal pathogen T. denticola is regulated via TLR2 (Shin, Kim et al. 2010). All these studies strongly suggest gingival epithelia are able to sense microbes, distinguish between commensal and periopathogenic bacteria, and regulate the appropriate responses for inflammation via regulation of AMPs. 


\subsubsection{Cathelicidin family - LL-37}

Cathelicidin AMPs are heterogeneous and share similar characteristics with other AMPs, such as a basic residue, overall amphipathic nature, and a net positive charge at neutral $\mathrm{pH}$ (Dale and Fredericks 2005). LL-37, the only member in human cathelicidin family, is transcribed by CAMP (cathelicidin antimicrobial peptide) gene, which translates to an 18 kDa proprotein (Zanetti, Gennaro et al. 2000; Zaiou, Nizet et al. 2003). This AMP is detected and expressed in higher amounts within neutrophils that migrate through the junctional epithelium to the gingival sulcus (Dale, Kimball et al. 2001). This peptide is present in a different site than beta-defensins, suggesting they could serve different role in periodontium. The expression of LL-37 is detected in wide range of epithelia and other body sites, including junctional epithelium, inflamed epidermal keratinocytes, tongue, buccal mucosa and saliva following inflammatory stimulation (Frohm, Agerberth et al. 1997; Frohm Nilsson, Sandstedt et al. 1999; Dale, Kimball et al. 2001; Murakami, Ohtake et al. 2002; Howell 2007). Junctional epithelium also expresses IL-8, following a gradient that leads to directional migration of neutrophils into the gingival sulcus when exposed to bacteria (Tonetti, Imboden et al. 1994). Thus, it is plausible that neutrophil migration through the tissue may be the reason for the expression of LL-37 in gingival epithelium (Dale, Kimball et al. 2001; Dale and Fredericks 2005). LL-37 has shown antimicrobial activities against periodontal pathogen A. actinomycetemcomitans (Gomez-Garces, Alos et al. 1994), while is ineffective against some cariogenic bacteria, including S. mutans, Streptococcus sobrinus and Actinomyces viscosus, as well as periodontal pathogen P. gingivalis (Altman, Steinberg et al. 2006).

\subsection{Differential expression of AMPs in periodontal health and disease}

How the expression of various AMPs varies during gingival and periodontal inflammation has been reported by various groups, and these studies show high inter-individual variability in both gene and protein expression of AMPs in patient samples (Dunsche, Acil et al. 2002; Lu, Jin et al. 2004; Dommisch, Acil et al. 2005; Lu, Samaranayake et al. 2005). Analyses of gene expression by RT-PCR showed hBD-1 and hBD-2 mRNA expression was less frequently detected in tissues with gingivitis than in healthy gingiva. In biopsies from patients with gingivitis, mRNA of hBD-1 and hBD-2 was detectable in $66 \%$ and $86 \%$ of samples, respectively, while $100 \%$ of all gingivitis samples showed the expression of hBD-3 mRNA (Dunsche, Acil et al. 2002). In addition, compared to the samples from healthy subjects, the level of beta-defensin mRNA expression was lower and less frequently found in samples from periodontitis patients (Dunsche, Acil et al. 2002; Bissell, Joly et al. 2004). Similar results have also been reported testing mRNA level by in situ hybridization and protein level using immunohistochemistry ( $\mathrm{Lu}$, Jin et al. 2004; Lu, Samaranayake et al. 2005; Hosokawa, Hosokawa et al. 2006). These studies suggest a decrease in the expression of hBD-2 and hBD-3 in both patient groups of gingivitis and periodontitis. However, other studies suggest differential expression of beta-defensins in patients with specific periodontal diseases, highlighting inter-individual variability in the expression of these AMPs. In samples collected from gingivitis and periodontitis patients, the amount of hBD-2 mRNA was up-regulated compared to the ones from healthy subjects, while the quantity of hBD-3 mRNA was equivalent in healthy and gingivitis groups, but increased in periodontitis samples (Dommisch, Acil et al. 2005). Quantitative RT-PCR analyses of hBD-1 and hBD-2 expression levels in gingiva of patients with gingivitis, aggressive periodontitis and chronic periodontitis found a significantly higher level of hBD-1 in chronic periodontitis group 
compared to gingivitis and aggressive periodontitis groups (Vardar-Sengul, Demirci et al. 2007). On the other hand, the expression level of hBD-2 was significantly higher in aggressive periodontitis group than in gingivitis and chronic periodontitis groups (VardarSengul, Demirci et al. 2007). The localization of beta-defensin protein expression also varied among different patient groups. The protein expression of hBD-1 and hBD-2 was mostly found in the granular and spinous cell layer in healthy and diseased gingival tissue samples (Lu, Jin et al. 2004). On the contrary, the expression of hBD-3 was found in basal cell layer in healthy samples, while in the basal and spinous cell layers in samples from periodontal disease (Lu, Samaranayake et al. 2005).

The levels of AMPs in GCF are thought to be associated with periodontal disease, as demonstrated by Puklo et al. that the GCF HNP1-3 levels were higher in patients with aggressive or chronic periodontitis when compared to healthy controls (Puklo, Guentsch et al. 2008). Gingival tissue samples from chronic periodontitis patients showed elevated mRNA expression and higher immunostaining of LL-37 on neutrophils, while the LL-37 levels were also elevated in the GCF of periodontitis patients (Hosokawa, Hosokawa et al. 2006; Turkoglu, Emingil et al. 2009; Turkoglu, Kandiloglu et al. 2011). In addition, patients with morbus Kostmann syndrome, an inherited disorder that causes lower than normal levels of neutrophils, have been found to be more susceptible to periodontal disease, while those with a bone marrow transplant are not (Putsep, Carlsson et al. 2002). The patients with Kostmann syndrome lack LL-37 in saliva and have lower concentrations of HNP1-3, the latter of which is commonly found in patients with other neutrophil disorders (Ganz, Metcalf et al. 1988). However, when these patients receive a bone marrow transplant, normal concentration of LL-37 is found in their saliva (Putsep, Carlsson et al. 2002). Of interesting to note is when patients with Kostmann syndrome have their levels of neutrophils restored via treatment with recombinant granulocyte-colony stimulating factor, they still experience recurring periodontal infections (Putsep, Carlsson et al. 2002; Carlsson, Wahlin et al. 2006). All these studies suggest that the deficiency in salivary LL-37 is a likely reason for chronic periodontitis in patients with morbus Kostmann prior to bone marrow transplant and further suggests a potential protective role in host defense by LL-37.

All the studies presented in this section demonstrate that AMPs are differentially expressed in various stages of periodontal health and disease. These studies also suggest that there may be complex regulatory mechanisms involved in gingival innate immunity (Chung, Dommisch et al. 2007), and further suggest AMPs play a crucial role in the maintenance of gingival health and prevention of periodontal disease.

\subsection{Potential therapeutic value of AMPs}

How AMPs maintain the delicate balance between oral health and dental plaque containing microbial consortium is still a matter of conjecture. Some hypotheses include AMPs creating physical holes that cause cellular contents to leak out, fatal depolarization of normally energized bacterial membrane, or the activation of deadly processes such as the induction of hydrolases that degrade the cell wall (Som, Vemparala et al. 2008). Overall, the mode of antimicrobial activity of AMPs has been most commonly attributed to disruption of cell membranes (Ganz and Lehrer 1999; Hancock and Diamond 2000), but a recent study also reported that defensins can inhibit cell wall biosynthesis via binding and sequestering of lipid II, a building block of bacterial cell wall (Wilmes, Cammue et al. 2011).

Currently, a combination of antimicrobial and mechanical applications is used in treatment plans for periodontal disease, such as applying tetracycline or doxycline families in 
conjunction to scaling and root planning. Recently, a sub-antimicrobial dose doxycyline has been introduced where low doses are given to block matrix metalloproteinases (MMP), which are capable of degrading extracellular matrix proteins (Tuter, Kurtis et al. 2007; Payne, Golub et al. 2011). Yet, antibiotic treatment for periodontal disease still poses a risk of developing antibiotic-resistant periodontal bacteria in the subgingival plaque (van Winkelhoff, Herrera Gonzales et al. 2000; Handal, Caugant et al. 2003; Maestre, Bascones et al. 2007; Ardila, Granada et al. 2010). AMPs have several advantages as therapeutics, including the broad spectrum of antimicrobial activity and do not appear to induce antibiotic resistance. AMPs as therapeutics against microbes would be promising because the target of AMPs are the bacterial membrane, thus to combat AMPs the bacteria would need to redesign its membrane, which would be a "costly" solution for most species (Zasloff 2002). The possibility of alleviating bacterial infections related to cystic fibrosis through increasing physiological levels of LL-37, or re-engineering human macrophages to express beta-defensins to enhance efficacy against Mycobacterium tuberculosis have been proposed (Bals, Weiner et al. 1999; Kisich, Heifets et al. 2001). However, limitations as an effective therapeutic are stalled by high production costs and the susceptibility to proteolytic degradation, a mechanism which microbial pathogens secrete proteases to counter-measure the target of AMPs (Peters, Shirtliff et al. 2010). Due to these limitations, a new pursuit has been made to construct synthetic mimics of AMPs, which would capture the important properties of AMPs but also eliminate problems related to drug therapy. Structurally these AMP mimics would maintain its amphiphillic topology to eventually depolarize the membrane potential and ultimately kill bacteria, but also possess a non-natural backbone without amide or ester function so the peptide will not undergo proteolytic degradation from bacterial enzymes (Tew, Liu et al. 2002; Tew, Clements et al. 2006; Hua, Scott et al. 2010). A recent study showed one mimetic called $\mathrm{mPE}$ was able to exhibit potency against biofilm cultures of $A$. actinomycetemcomitans and $P$. gingivalis, while also inhibiting IL-1Binduced secretion of IL-8 in gingival epithelial cells (Hua, Scott et al. 2010). The antiinflammatory activity was followed with a reduced activation of NF- $\mathrm{KB}$, suggesting that these AMP mimics could act as an anti-biofilm and anti-inflammatory agent. Furthermore, it has been shown in bacterial resistance studies that Staphylococcus aureus showed increased minimum inhibitory concentration (MIC) for conventional antibiotics, but no change was observed with MIC for mPE (Beckloff, Laube et al. 2007; Hua, Scott et al. 2010). However, a current limitation of mimetic is that it has been tested on single bacterium but not on complex biofilm structures.

\section{Proteases vs. protease inhibitors in periodontal health and disease}

\subsection{Various classes of protease inhibitors in gingival epithelia}

Serine protease inhibitors play a critical role in host tissue homeostasis, as gingival epithelia secrete these protease inhibitors as a way to protect the tissue from excessive damage by proteases, which can be of pathogenic bacteria or of neutrophil origin. Thus, the balance between proteases and their inhibitors contributes to maintenance of tissue integrity (Magert, Drogemuller et al. 2005). These protease inhibitors include secretory leukocyte protease inhibitor (SLPI), elastase-specific inhibitor (ELAFIN) and squamous cell carcinoma antigen (SCCA). SLPI is found in a variety of mucous secretions, including in GCF from sites of periodontal disease (Minami 1999). This protease inhibitor protects tissues from destruction during an inflammatory response via regulating the activity of neutrophil 
elastase (Giannopoulou, Di Felice et al. 1990). ELAFIN, also known as skin-derived antileukoproteinase (SKALP), is expressed in human epithelia of the tongue, palate, lingual tonsils, pharynx as well as gingiva (Molhuizen and Schalkwijk 1995). ELAFIN has been shown to inhibit neutrophil elastase and proteinase 3, thus has a role in protecting tissue from degradation by the neutrophil enzymes (Ying and Simon 1993; Zani, Nobar et al. 2004). ELAFIN and SLPI are chelonianin family of serine protease inhibitors and share $40 \%$ sequence identity (Ying and Simon 1993; Zani, Nobar et al. 2004; Guyot, Butler et al. 2008). Both SLPI and ELAFIN have antimicrobial activity against Gram-positive as well as Gramnegative pathogens (Sallenave, Cunningham et al. 2003; McMichael, Maxwell et al. 2005; King, Wheelhouse et al. 2009).

SCCA1 and SCCA2 are members of the ovalbumin-serpin and serve as a marker for certain inflammatory conditions. Within the mucous membranes lined with squamous epithelia, coexpression of SCCA1 and 2 plays an important role in the coordinated regulation of certain serine and cysteine proteases associated with both normal and transformed cells (Cataltepe, Gornstein et al. 2000). SCCA1 and SCCA2 share 91\% homology at the amino acid level, and both are induced by IL-4 and IL-13 (Yuyama, Davies et al. 2002; Mitsuishi, Nakamura et al. 2005). However, their functions differ: SCCA1 inhibits cysteine proteases such as cathepsin $\mathrm{K}$, while SCCA2 inhibits serine proteases such as cathepsin $\mathrm{G}$ and human mast cell chymase (Silverman, Bird et al. 2001).

These protease inhibitors are expressed by various epithelial cells and act as an anti-protease to protect against tissue damages caused during inflammation (Alkemade, Molhuizen et al. 1994; Pfundt, van Ruissen et al. 1996; van Wetering, van der Linden et al. 2000). In addition, other studies demonstrated anti-bacterial and anti-inflammatory activities of ELAFIN that are independent of anti-protease activity (Simpson, Maxwell et al. 1999; Meyer-Hoffert, Wichmann et al. 2003). In the context of the periodontium, these protease inhibitors produced by GECs might protect against bacterial proteases and limit tissue damage due to neutrophil proteases associated with inflammation. Thus, the balance between protease inhibitors and proteases may be a factor in the progression of disease.

\subsection{Regulation of protease inhibitors by periodontal pathogens}

The development of periodontal disease is characterized by the transition of the subgingival flora from Gram-positive complex, such as Streptococci, to a Gram-negative complex including the presumptive pathogen, $P$. gingivalis (Kolenbrander, Andersen et al. 2002). P. gingivalis gingipains are cysteine proteases with specificity for cleavage at either arginine (Rgp) or lysine (Kgp) (Potempa, Pike et al. 1995; Potempa and Travis 1996). Rgp activates cellular responses of both epithelial cells and fibroblasts via PAR2 and up-regulates inflammatory and innate immune responses (Lourbakos, Potempa et al. 2001; Holzhausen, Spolidorio et al. 2006). In addition to $P$. gingivalis, periodontal pathogens $T$. denticola and T. forsythia also have serine or cysteine proteases as their main virulence factors, and these proteases play a role in periodontitis (Fenno, Lee et al. 2001; van der Reijden, Bosch-Tijhof et al. 2006). F. nucleatum is a common microorganism within the periodontium in both healthy and diseased tissue and serves as a bridging organism between commensals and pathogens. Previous studies reported F. nucleatum as well as commensal bacterium S. gordonii have serine-type proteases which are involved in the degradation of collagen and/or fibronectin (Juarez and Stinson 1999; Bachrach, Rosen et al. 2004). In addition to bacterial proteases, neutrophils also release proteases. In the normal epithelium, neutrophils flow into the space between the tooth and soft tissue due to the 
cytokine gradient. Although neutrophils serve as part of the continuous surveillance of the gingival sulcus, proteases released by neutrophils contribute to inflammation and tissue damage (Tonetti, Imboden et al. 1998; Nathan 2006).

Our laboratory previously showed that GECs exposed to F. nucleatum up-regulated expression of multiple protease inhibitors as well as antimicrobial peptides and other potentially protective factors (Table 1) (Yin and Dale 2007). Our data suggest that F. nucleatum, a bridging organism between non-pathogenic commensal and pathogenic bacteria, enhances expression of protease inhibitors that protect GECs in anticipation of virulent proteases secreted by pathogenic bacteria. Both host cell-derived proteases, such as neutrophil elastase, and pathogen-derived proteases, such as the gingipains, are targeted by these protease inhibitors, and therefore, the protease inhibitors may play an important role in maintaining the extent of inflammatory tissue damage (Into, Inomata et al. 2006; Williams, Brown et al. 2006; Yin, Swanson et al. 2010).

\begin{tabular}{|l|l|l|l|}
\hline $\begin{array}{l}\text { Protease } \\
\text { Inhibitor }\end{array}$ & Target Protease & Potential Function & $\begin{array}{l}\text { Fold } \\
\text { Change* }\end{array}$ \\
\hline ELAFIN & Elastase, PMN & $\begin{array}{l}\text { Innate immunity, } \\
\text { antimicrobial }\end{array}$ & 14.31 \\
\hline SERPINB1 & $\begin{array}{l}\text { Elastase, Cathepsin } \\
\text { G }\end{array}$ & $\begin{array}{l}\text { Innate immunity, inhibits } \\
\text { PMN proteases }\end{array}$ & 3.2 \\
\hline SERPINB2 & Thrombin & $\begin{array}{l}\text { Regulates extravascular } \\
\text { plasminogen activation }\end{array}$ & 2.2 \\
\hline SCCA1 & Cathepsin S, K, L & $\begin{array}{l}\text { Inhibits Cathepsin S, K, L } \\
\text { and modulates host } \\
\text { immune response }\end{array}$ & 19.4 \\
\hline SCCA2 & Cathepsin G & Inhibits mast cell proteases & 8.6 \\
\hline SLPI & $\begin{array}{l}\text { Elastase, Trypsin, } \\
\text { Cathepsin B }\end{array}$ & $\begin{array}{l}\text { Stimulates wound healing, } \\
\text { inhibits PMN proteases }\end{array}$ & 4.3 \\
\hline Cystatin B & Stefin B & $\begin{array}{l}\text { Protection against } \\
\text { intracellular proteases }\end{array}$ & 2.0 \\
\hline
\end{tabular}

*Fold increase after stimulation with F. nucleatum cell wall extract for $24 \mathrm{~h}$ compared to unstimulated.

Table 1. Changes in the induction level of various protease inhibitors in gingival epithelial cells following stimulation with F. nucleatum (Yin and Dale 2007).

These protease inhibitors are also affected by perio-pathogenic organism $P$. gingivalis, whose main virulence factors are cysteine proteases. A protective effect of these protease inhibitors in gingival health is shown by our study that demonstrated pre-treatment of GECs with SLPI, SCCA1 or SCCA2 partially attenuated antimicrobial proteins hBD-2 and CCL20 mRNA expression in response to $P$. gingivalis (Yin, Swanson et al. 2010). However, the same study showed the presence of $P$. gingivalis disrupted the function of these serine protease inhibitors, suggesting that the presence of an organism colonizing oral plaque prior to the establishment by pathogens enhances expression of protease inhibitors that protect GECs, while P. gingivalis secretes proteases that degrade cellular protease inhibitors (Yin, Swanson et al. 2010). It is of interest to note that various periodontal pathogens which secrete proteases $(P$. gingivalis, $T$. forsythia, A. actinomycetemcomitans) were tested, but $P$. gingivalis was most effective at degrading protease inhibitors (Figure 2) (Yin, Swanson et al. 2010). The degradation of 
protease inhibitors by $P$. gingivalis may result in decreased host protective capacity, and the balance between cellular protease inhibitors and their degradation by $P$. gingivalis and/or other periodontal pathogens may be an important factor in susceptibility to $P$. gingivalis infection. The dominance of $P$. gingivalis in the degradation of protease inhibitors is important to note, since during the formation of dental plaque, protease inhibitors may be induced as a host protective mechanism by the presence of non-pathogenic bacteria, but may become ineffective once protease-secreting pathogens are established.

\section{gingivalis \\ T. forsythia \\ F. nucleatum}

A. actinomycetemcomitans
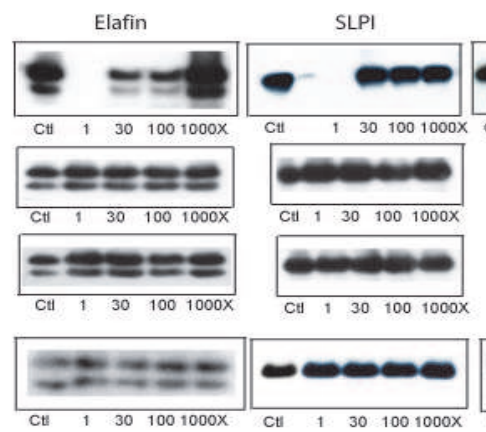
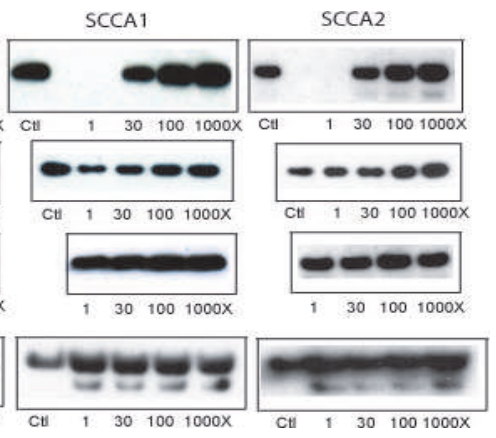

Fig. 2. Recombinant SLPI, ELAFIN, SCCA1, and SCCA2 are degraded by $P$. gingivalis supernatants in vitro in a dose-dependent manner. Western Blot analysis for each protease inhibitor using a constant concentration of recombinant protease inhibitor incubated with cellfree supernatants of oral bacteria for $15 \mathrm{~min}$ at RT. The undiluted supernatant (1) corresponds to MOI 100; increasing dilution factor is indicated below each protease inhibitor. Control: recombinant protein only. The controls shown with $P$. gingivalis also apply to the recombinant proteins treated with T. forsythia and F. nucleatum (Yin, Swanson et al. 2010). Permission from Co-Action Publishing.

In addition to exposure to proteases secreted by oral pathogenic bacteria, oral cavity may also be exposed to different neutrophil-derived serine proteases, such as human leukocyte elastase, cathepsin G and proteinase 3 (Sugawara, Uehara et al. 2001; Uehara, Muramoto et al. 2003). These neutrophil proteases may be secreted in response to the presence of oral bacteria, and thus oral cavity may be exposed to these neutrophil proteases prior to being exposed to proteases from periodontal pathogens. In addition, protease inhibitors are likely to have different effects on neutrophil proteases secreted by host vs. proteases secreted by periodontal pathogens: proteases secreted by pathogens may degrade host protease inhibitors; while proteases secreted by host neutrophils may maintain more natural balance in maintaining epithelial health. Proteases have to be at the right place at the right time to have an effect on the host, thus have to be tightly regulated by the host. Therefore, the balance between the proteases and protease inhibitors is crucial in the health of oral epithelia.

\subsection{Changes in protease inhibitor levels in periodontitis}

Periodontitis is a chronic inflammatory disease whose main etiologic agents include Gramnegative anaerobic bacteria and spirochetes (Haffajee and Socransky 1994). Among them, $P$. gingivalis in particular plays a significant role in the progression of chronic periodontitis (O'Brien-Simpson, Veith et al. 2004). Many virulence factors of this pathogen include proteases (gingipains), fimbriae and hemagglutinins (Amano 2003; Veith, Chen et al. 2004; 
Into, Inomata et al. 2006). P. gingivalis gingipains have shown to degrade extracellular matrix components such as laminin, fibronectin, and collagen type III, IV, and V in vitro (Potempa, Banbula et al. 2000), and are thought to account for at least $85 \%$ of the general proteolytic activity displayed by $P$. gingivalis (Imamura 2003). Our previous in vitro study found that the secretion of SLPI and ELAFIN was significantly reduced in response to $P$. gingivalis and that $P$. gingivalis supernatants digested recombinant SLPI, ELAFIN, SCCA1 and 2 (Figure 2) (Yin, Swanson et al. 2010). These data suggest degradation of protease inhibitors by $P$. gingivalis may result in decreased host protective capacity and higher susceptibility to $P$. gingivalis infection (Yin, Swanson et al. 2010).

As a follow-up to this in vitro study, an in vivo study from our group correlated the amount of $P$. gingivalis in subgingival plaque of patients with chronic periodontitis with the level of protease inhibitors in GCF of healthy and periodontitis patients. Significantly lower levels of SLPI and ELAFIN were detected in subjects with periodontitis and P. gingivalis present in their plaque compare to healthy controls (Kretschmar, Yin et al. 2011). The level of SLPI was also decreased in GCF of periodontal patients without detectable level of $P$. gingivalis in their subgingival plaque. And an inverse correlation was observed between the ELAFIN and SLPI concentrations and the number of $P$. gingivalis present in subgingival plaque. Our findings showed that host-derived protease inhibitors SLPI and ELAFIN, which are secreted as a response to environmental and microbial stimuli, are decreased in concentration in periodontal pockets with $P$. gingivalis. The reduced concentrations of these protective protease inhibitors may contribute to the loss of host defense capacity and increase susceptibility to breakdown from chronic infection.

Similarly, a separate study reported when SLPI concentrations in GCF from active periodontitis patients and periodontitis patients in maintenance were compared, SLPI was significantly reduced in the group with high amount of $P$. gingivalis (Into, Inomata et al. 2006). The proteolytic activity of $P$. gingivalis gingipain isoform RgpA is thought to be responsible for this observation (Into, Inomata et al. 2006). Although the overall bacterial load in these samples was not specified, the data from this study is in agreement with our previous study utilizing $P$. gingivalis mutant strains lacking various gingipains (Yin, Swanson et al. 2010). In addition to the role RgpA may play in the degradation of SLPI, the bacterial biofilm may also play a role in the degradation of protease inhibitors, such as increased neutrophil elastase level as a result of high bacterial load in dental plaque.

\section{Epigenetic regulation and its implication on periodontal disease}

Epigenetics is heritable and reversible changes in gene expression without altering DNA sequence. Chromatin structure is made up of eight histone molecules (two each of H2A, H2B, $\mathrm{H} 3$ and $\mathrm{H} 4$ ) and DNA which winds around these proteins. Histones are subject to a number of post-translational modifications, such as acetylation, methylation, phosphorylation and ubiquitination (Hansen, Tse et al. 1998; Strahl and Allis 2000). The mechanisms of epigenetic modifications include histone acetylation, histone methylation and DNA methylation, and these modifications provide a way to control the expression of genes involved in various cellular functions as well as in cancer (Egger, Liang et al. 2004; Rodenhiser and Mann 2006). Enzymes involved in these epigenetic mechanisms are: histone acetyltransferases (HATs); histone deacetylases (HDACs); histone methyltransferases (HMTs); and DNA methyltransferases (DNMTs) (Figure 3). Modifications on chromatin structure can occur in response to diet, inherited polymorphisms in certain genes and to environmental toxins 
(Sutherland and Costa 2003; Luch 2005; Rodenhiser and Mann 2006). When histones are acetylated, transcription factors can access DNA, leading to gene transcription, while deacetylated histones lead to condensed (or closed) chromatin structure, making DNA inaccessible to transcription factors and preventing gene expression (Figure 3). In addition, methylation of cytosine residues at $\mathrm{CpG}$ sites in DNA inhibits binding of transcription factors, leading to gene silencing. Methylation of gene promoter region is one of the most common epigenetic mechanisms in silencing tumor suppressor genes, and over-expression of DNMTs in humans is associated with a variety of cancers (Rodenhiser and Mann 2006). Furthermore, decreased methyltransferase activity and hypo-methylated DNA have been associated with autoimmune diseases (Richardson 2003; Oelke and Richardson 2004), and changes in the histone acetylation in central nervous system has been linked to cognitive decline in a mouse model (Peleg, Sananbenesi et al. 2010). Although various epigenetic mechanisms work in concert to produce long-term and stable regulation of gene expression, not much is known on how these processes are linked and how specific patterns of epigenetic modification are inherited.

A recent study reported that oral squamous cell carcinoma showed epigenetic changes associated with SERPINE1 expression (Gao, Nielsen et al. 2010), while other studies suggest that epigenetics play a critical role in regulating inflammatory responses and that the manifestation and severity of periodontal disease may be influenced by epigenetic factors (Bobetsis, Barros et al. 2007; Offenbacher, Barros et al. 2008). Many patients with the same clinical symptoms respond differently to the same therapy, suggesting the inter-individual variability observed as a clinical outcome of the disease is influenced by genetic (Schenkein 2002; Feinberg 2007) as well as epigenetic factors (Offenbacher, Barros et al. 2008). Epigenetic modifications alter patterns of gene expression, which in turn leads to various clinical outcomes. Furthermore, variations in epigenetic status will likely elicit diverse inflammatory responses. A new study from our group focused on finding answers to how epigenetic modifications brought on by exposure to oral bacteria, including periodontal pathogens, affect host innate immune responses and susceptibility to subsequent infections (Yin and Chung 2011).

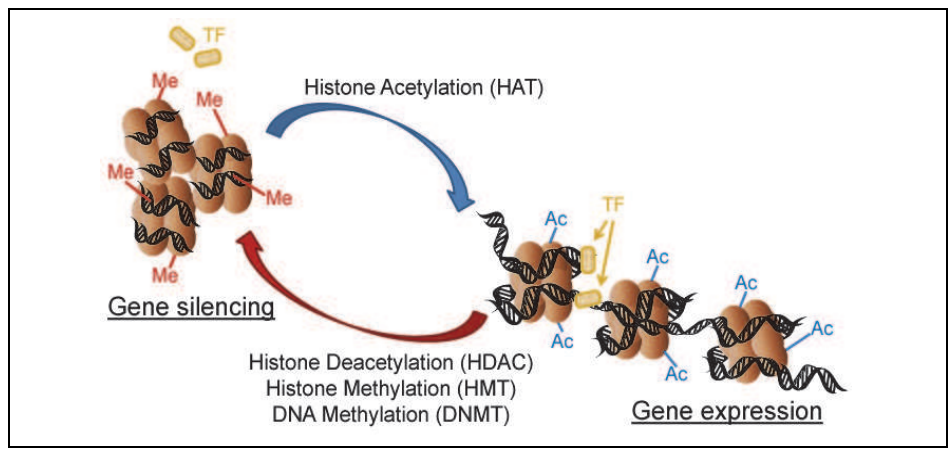

Fig. 3. Histone acetylation allows open chromatic structure, and transcription factors can access DNA. Deacetylation of histones as well as histone methylation and DNA methylation result in closed chromatin, thus transcription factors cannot access DNA, which results in gene silencing. Epigenetic modifications of histones and/or DNA via methylation lead to altered gene expression. TF: transcription factors; Ac: acetylation; Me: methylation; HAT: histone acetyltransferase; HDAC: histone deacetylase; HMT: histone methyltransferase; DNMT: DNA methyltransferase. 
When any changes in the expression levels of enzymes involved in the epigenetic modification after GECs were exposed to oral bacteria were investigated, we found the expression of histone deacetylases and DNA methyltransferase changed in response to the presence of oral bacteria. Histone deacetylases (HDACs) remove acetyl groups from histone, leading to suppression of genes, while DNA methyltransferases (DNMTs) catalyze transfer of methyl groups onto DNA, which also leads to gene suppression (Figure 3). Quantitative real-time PCR analyses showed changes in the expression levels of these genes when GECs were treated with $P$. gingivalis or F. nucleatum at various multiplicities of infection for 1, 4, 24 and $48 \mathrm{~h}$. The gene expression levels of DNMT1, HDAC1 and HDAC2 decreased in GECs treated with $P$. gingivalis or F. nucleatum, although the levels of decrease differed between bacterial species and/or exposure time (Yin and Chung 2011). As changes in the expression of enzymes catalyzing epigenetic modifications were observed, it was also of interest to note the changes in methylation levels of various genes in GECs after the cells were exposed to these oral bacteria. Studies utilizing methylation PCR Array showed a dose-dependent and statistically significant increase in methylation levels of the following genes after GECs were exposed to $P$. gingivalis: CD276, an immune regulator; elastase 2, a serine protease that plays a role in inflammatory diseases; INHBA, a tumor-suppressing protein; GATA 3, a putative tumor suppressor; TLR2; and IL-12A. Stimulation of GECs with $P$. gingivalis also resulted in hypo-methylation of ZNF287, a member of Zinc finger protein family. The up-regulation of Zinc finger proteins has been associated with cardiovascular disease (Dai and Liew 1999), thus this observation is in line with recent studies linking periodontal disease with increased risk of systemic disease (Persson and Persson 2008). GECs exposed to P. gingivalis also showed a decrease in the methylation of STAT5A, which mediates cellular responses to cytokines IL-2, IL-3, IL-7, GM-CSF and plays a role in progression of tumors. On the other hand, the methylation levels of elastase 2 and GATA3 decreased significantly after cells were stimulated with F. nucleatum (Yin and Chung 2011). Interestingly, only F. nucleatum induced hyper-methylation of MALT1 (Mucosa-associated lymphoid tissue lymphoma translocation gene) in GECs. MALT1 induces IKK catalytic activity, resulting in NFKB activation in immune cells (Schulze-Luehrmann and Ghosh 2006). The methylation of MALT1 is associated with silencing of MALT1 gene, which is consistent with our previous reports that $F$. nucleatum does not utilize the NFKB signaling pathway in the induction of innate immune responses (Chung and Dale 2004; Chung and Dale 2008). Taken together, these data suggest that epigenetic modification of genes, whose function is associated with growth control and inflammation, is differentially regulated by different oral bacteria (Yin and Chung 2011).

Modulations of chromatin structure play an important role in the regulation of transcription, and these modifications directly affect the accessibility of chromatin to transcription factors, thus on gene expression. When the changes in histone H3 level in GECs after exposure to periopathogen vs. non-pathogen were examined, the endogenous level of histone $\mathrm{H} 3$ that is tri-methylated at Lys4 was significantly decreased following stimulated with $P$. gingivalis compared to unstimulated control, while the level increased after exposure to F. nucleatum (Yin and Chung 2011). Our data suggest these two bacterial species, pathogen vs. nonpathogen, differentially regulate $\mathrm{H} 3 \mathrm{~K} 4$ methylation and further suggest bacterial infection in oral epithelia is associated with changes in H3K4 methylation (Yin and Chung 2011).

Gene promoter methylation is the most common epigenetic mechanism silencing tumor suppressor genes during oncogenesis. Almost all cancer-related signaling pathways are affected by methylation, and the number of genes affected in each major type of cancer is 
still rapidly growing. However, even the most relevant genes have not yet been correlated to individual cancer types for development of DNA methylation biomarkers. Recent studies reported that particular histone modifications are correlated with certain types of cancers and that histone modifications will be useful biomarkers for cancer ( $\mathrm{Su}$, Lucas et al. 2009; Manuyakorn, Paulus et al. 2010; Svotelis, Gevry et al. 2010). Since our recent data strongly suggest presence of oral bacteria affects chromatin modification in GECs, it is plausible periodontal patients with high number of periodontal pathogens recovered from the oral cavity will show altered chromatin modifications. Further studies are needed to identify epigenetic factors involved in development and pathogenesis of periodontitis, contributing to better defining of epigenetic modifications as an indicator of periodontal disease. It would be of importance in a periodontal treatment plan to identify a certain species of bacteria which induce epigenetic changes and subsequently modify host responses. Furthermore, better understanding of specific bacteria that show capacity to induce epigenetic changes would be of importance in developing specific therapeutic strategies for each patient.

\section{Conclusion}

Periodontitis is a disease that is not only caused by one single bacterium, but by a number of different bacterial species, organized in a complex biofilm and thereby exhibiting various properties. Understanding how gingival epithelia response to the presence of different commensals and pathogens, leading to induction of appropriate innate immune responses, will provide significant new insights into this complex biological system in the oral epithelia. Furthermore, better understanding the role of other factors influencing periodontal health, such as the balance between proteases and protease inhibitors, and the role epigenetic status plays in health and disease, will have direct implications for new understanding of oral innate immune responses and the development of potential new and innovative therapeutic interventions for periodontal disease.

\section{Acknowledgments}

Supported by NIH/NIDCR grants R01 DE013573 and DE19632

\section{References}

Alkemade, J. A., H. O. Molhuizen, et al. (1994). "SKALP/elafin is an inducible proteinase inhibitor in human epidermal keratinocytes." J Cell Sci 107 ( Pt 8): 2335-42.

Altman, H., D. Steinberg, et al. (2006). "In vitro assessment of antimicrobial peptides as potential agents against several oral bacteria." J Antimicrob Chemother 58(1): 198201.

Amano, A. (2003). "Molecular interaction of Porphyromonas gingivalis with host cells: implication for the microbial pathogenesis of periodontal disease." J Periodontol 74(1): 90-6.

Ardila, C. M., M. I. Granada, et al. (2010). "Antibiotic resistance of subgingival species in chronic periodontitis patients." J Periodontal Res 45(4): 557-63.

Armitage, G. C. (1999). "Development of a classification system for periodontal diseases and conditions." Ann Periodontol 4(1): 1-6. 
Bachrach, G., G. Rosen, et al. (2004). "Identification of a Fusobacterium nucleatum 65 kDa serine protease." Oral Microbiol Immunol 19(3): 155-9.

Bals, R., D. J. Weiner, et al. (1999). "Transfer of a cathelicidin peptide antibiotic gene restores bacterial killing in a cystic fibrosis xenograft model." J Clin Invest 103(8): 1113-7.

Bals, R. and J. M. Wilson (2003). "Cathelicidins--a family of multifunctional antimicrobial peptides." Cell Mol Life Sci 60(4): 711-20.

Beckloff, N., D. Laube, et al. (2007). "Activity of an antimicrobial peptide mimetic against planktonic and biofilm cultures of oral pathogens." Antimicrob Agents Chemother 51(11): 4125-32.

Bissell, J., S. Joly, et al. (2004). "Expression of beta-defensins in gingival health and in periodontal disease." J Oral Pathol Med 33(5): 278-85.

Bobetsis, Y. A., S. P. Barros, et al. (2007). "Bacterial infection promotes DNA hypermethylation." J Dent Res 86(2): 169-74.

Brancatisano, F. L., G. Maisetta, et al. (2011). "Reduced human beta defensin 3 in individuals with periodontal disease." J Dent Res 90(2): 241-5.

Buduneli, N., H. Baylas, et al. (2005). "Periodontal infections and pre-term low birth weight: a case-control study." J Clin Periodontol 32(2): 174-81.

Carlsson, G., Y. B. Wahlin, et al. (2006). "Periodontal disease in patients from the original Kostmann family with severe congenital neutropenia." J Periodontol 77(4): 744-51.

Cataltepe, S., E. R. Gornstein, et al. (2000). "Co-expression of the squamous cell carcinoma antigens 1 and 2 in normal adult human tissues and squamous cell carcinomas." J Histochem Cytochem 48(1): 113-22.

Chung, W. O. and B. A. Dale (2004). "Innate immune response of oral and foreskin keratinocytes: utilization of different signaling pathways by various bacterial species." Infect Immun 72(1): 352-8.

Chung, W. O. and B. A. Dale (2008). "Differential utilization of nuclear factor-kappaB signaling pathways for gingival epithelial cell responses to oral commensal and pathogenic bacteria." Oral Microbiol Immunol 23(2): 119-26.

Chung, W. O., D. R. Demuth, et al. (2000). "Identification of a Porphyromonas gingivalis receptor for the Streptococcus gordonii SspB protein." Infect Immun 68(12): 675862.

Chung, W. O., H. Dommisch, et al. (2007). "Expression of defensins in gingiva and their role in periodontal health and disease." Curr Pharm Des 13(30): 3073-83.

Chung, W. O., S. R. Hansen, et al. (2004). "Protease-activated receptor signaling increases epithelial antimicrobial peptide expression." J Immunol 173(8): 5165-70.

Cole, A. M., P. Dewan, T. Ganz (1999). "Innate antimicrobial activity of nasal secretions." Infect Immun 67: 3267-3275.

Crawford, J. M., J. M. Wilton, et al. (2000). "Neutrophils die in the gingival crevice, periodontal pocket, and oral cavity by necrosis and not apoptosis." J Periodontol 71(7): 1121-9.

Cunliffe, R. N. (2003). "Alpha-defensins in the gastrointestinal tract." Mol Immunol 40(7): 463-7.

Dai, K. S. and C. C. Liew (1999). "Chromosomal, in silico and in vitro expression analysis of cardiovascular-based genes encoding zinc finger proteins." J Mol Cell Cardiol 31(9): 1749-69. 
Dale, B. A. (2002). "Periodontal epithelium: a newly recognized role in health and disease." Periodontol 2000 30: 70-8.

Dale, B. A. and L. P. Fredericks (2005). Antimicrobial Peptides in the Oral Environment. Antimicrobial Peptides in Human Health and Disease. R. M. Gallo. San Diego, Horizon Bioscience: 223-252.

Dale, B. A. and L. P. Fredericks (2005). "Antimicrobial peptides in the oral environment: expression and function in health and disease." Curr Issues Mol Biol 7(2): 119-33.

Dale, B. A., J. R. Kimball, et al. (2001). "Localized antimicrobial peptide expression in human gingiva." J Periodontal Res 36(5): 285-94.

Diamond, D. L., J. R. Kimball, et al. (2001). "Detection of beta-defensins secreted by human oral epithelial cells." J Immunol Methods 256(1-2): 65-76.

Diamond, G., J. P. Russell, et al. (1996). "Inducible expression of an antibiotic peptide gene in lipopolysaccharide-challenged tracheal epithelial cells." Proc Natl Acad Sci U S A 93(10): 5156-60.

Dommisch, H., Y. Acil, et al. (2005). "Differential gene expression of human beta-defensins (hBD-1, -2, -3) in inflammatory gingival diseases." Oral Microbiol Immunol 20(3): 186-90.

Dommisch, H., W. O. Chung, et al. (2007). "Protease-activated receptor 2 mediates human beta-defensin 2 and CC chemokine ligand $20 \mathrm{mRNA}$ expression in response to proteases secreted by Porphyromonas gingivalis." Infect Immun 75(9): 4326-33.

Dunsche, A., Y. Acil, et al. (2002). "The novel human beta-defensin-3 is widely expressed in oral tissues." Eur J Oral Sci 110(2): 121-4.

Egger, G., G. Liang, et al. (2004). "Epigenetics in human disease and prospects for epigenetic therapy." Nature 429(6990): 457-63.

Feinberg, A. P. (2007). "Phenotypic plasticity and the epigenetics of human disease." Nature 447(7143): 433-40.

Fenno, J. C., S. Y. Lee, et al. (2001). "The opdB locus encodes the trypsin-like peptidase activity of Treponema denticola." Infect Immun 69(10): 6193-200.

Feucht, E. C., C. L. DeSanti, et al. (2003). "Selective induction of human beta-defensin mRNAs by Actinobacillus actinomycetemcomitans in primary and immortalized oral epithelial cells." Oral Microbiol Immunol 18(6): 359-63.

Frohm, M., B. Agerberth, et al. (1997). "The expression of the gene coding for the antibacterial peptide LL-37 is induced in human keratinocytes during inflammatory disorders." J Biol Chem 272(24): 15258-63.

Frohm Nilsson, M., B. Sandstedt, et al. (1999). "The human cationic antimicrobial protein (hCAP18), a peptide antibiotic, is widely expressed in human squamous epithelia and colocalizes with interleukin-6." Infect Immun 67(5): 2561-6.

Ganz, T. and R. I. Lehrer (1994). "Defensins." Curr Opin Immunol 6(4): 584-9.

Ganz, T. and R. I. Lehrer (1999). "Antibiotic peptides from higher eukaryotes: biology and applications." Mol Med Today 5(7): 292-7.

Ganz, T., J. A. Metcalf, et al. (1988). "Microbicidal/cytotoxic proteins of neutrophils are deficient in two disorders: Chediak-Higashi syndrome and "specific" granule deficiency." J Clin Invest 82(2): 552-6.

Ganz, T., M. E. Selsted, et al. (1985). "Defensins. Natural peptide antibiotics of human neutrophils." J Clin Invest 76(4): 1427-35. 
Gao, S., B. S. Nielsen, et al. (2010). "Epigenetic alterations of the SERPINE1 gene in oral squamous cell carcinomas and normal oral mucosa." Genes Chromosomes Cancer 49(6): 526-38.

Giannopoulou, C., R. Di Felice, et al. (1990). "Synthesis of alpha 2-macroglobulin in human gingiva: a study of the concentration of macroglobulin and albumin in gingival fluid and serum." Arch Oral Biol 35(1): 13-6.

Gomez-Garces, J. L., J. I. Alos, et al. (1994). "Bacteremia by multidrug-resistant Capnocytophaga sputigena." J Clin Microbiol 32(4): 1067-9.

Guyot, N., M. W. Butler, et al. (2008). "Elafin, an elastase specific inhibitor, is cleaved by its cognate enzyme neutrophil elastase in sputum from individuals with cystic fibrosis." J Biol Chem.

Haffajee, A. D. and S. S. Socransky (1994). "Microbial etiological agents of destructive periodontal diseases." Periodontol 2000 5: 78-111.

Hancock, R. E. and D. S. Chapple (1999). "Peptide antibiotics." Antimicrob Agents Chemother 43(6): 1317-23.

Hancock, R. E. and G. Diamond (2000). "The role of cationic antimicrobial peptides in innate host defences." Trends Microbiol 8(9): 402-10.

Hancock, R. E. and M. G. Scott (2000). "The role of antimicrobial peptides in animal defenses." Proc Natl Acad Sci U S A 97(16): 8856-61.

Handal, T., D. A. Caugant, et al. (2003). "Antibiotic resistance in bacteria isolated from subgingival plaque in a norwegian population with refractory marginal periodontitis." Antimicrob Agents Chemother 47(4): 1443-6.

Hansen, J. C., C. Tse, et al. (1998). "Structure and function of the core histone N-termini: more than meets the eye." Biochemistry 37(51): 17637-41.

Holzhausen, M., L. C. Spolidorio, et al. (2006). "Protease-activated receptor-2 activation: a major role in the pathogenesis of Porphyromonas gingivalis infection." Am J Pathol 168(4): 1189-99.

Hosokawa, I., Y. Hosokawa, et al. (2006). "Innate immune peptide LL-37 displays distinct expression pattern from beta-defensins in inflamed gingival tissue." Clin Exp Immunol 146(2): 218-25.

Howell, M. D. (2007). "The role of human beta defensins and cathelicidins in atopic dermatitis." Curr Opin Allergy Clin Immunol 7(5): 413-7.

Hua, J., R. W. Scott, et al. (2010). "Activity of antimicrobial peptide mimetics in the oral cavity: II. Activity against periopathogenic biofilms and anti-inflammatory activity." Mol Oral Microbiol 25(6): 426-32.

Imamura, T. (2003). "The role of gingipains in the pathogenesis of periodontal disease." J Periodontol 74(1): 111-8.

Into, T., M. Inomata, et al. (2006). "Arginine-specific gingipains from Porphyromonas gingivalis deprive protective functions of secretory leucocyte protease inhibitor in periodontal tissue." Clin Exp Immunol 145(3): 545-54.

Juarez, Z. E. and M. W. Stinson (1999). "An extracellular protease of Streptococcus gordonii hydrolyzes type IV collagen and collagen analogues." Infect Immun 67(1): 271-8.

Kinane, D. and P. Bouchard (2008). "Periodontal diseases and health: Consensus Report of the Sixth European Workshop on Periodontology." J Clin Periodontol 35(8 Suppl): 333-7. 
Kinane, D. F. and T. C. Hart (2003). "Genes and gene polymorphisms associated with periodontal disease." Crit Rev Oral Biol Med 14(6): 430-49.

King, A. E., N. Wheelhouse, et al. (2009). "Expression of secretory leukocyte protease inhibitor and elafin in human fallopian tube and in an in-vitro model of Chlamydia trachomatis infection." Hum Reprod 24(3): 679-86.

Kisich, K. O., L. Heifets, et al. (2001). "Antimycobacterial agent based on mRNA encoding human beta-defensin 2 enables primary macrophages to restrict growth of Mycobacterium tuberculosis." Infect Immun 69(4): 2692-9.

Kohlgraf, K. G., A. Ackermann, et al. (2010). "Defensins attenuate cytokine responses yet enhance antibody responses to Porphyromonas gingivalis adhesins in mice." Future Microbiol 5(1): 115-25.

Kolenbrander, P. E., R. N. Andersen, et al. (2002). "Communication among oral bacteria." Microbiol Mol Biol Rev 66(3): 486-505, table of contents.

Kretschmar, S., L. Yin, et al. (2011). "Protease inhibitor levels in periodontal health and disease." J Perio Res, In press.

Krisanaprakornkit, S., J. R. Kimball, et al. (2002). "Regulation of human beta-defensin-2 in gingival epithelial cells: the involvement of mitogen-activated protein kinase pathways, but not the NF-kappaB transcription factor family." J Immunol 168(1): 316-24.

Krisanaprakornkit, S., J. R. Kimball, et al. (2000). "Inducible expression of human betadefensin 2 by Fusobacterium nucleatum in oral epithelial cells: multiple signaling pathways and role of commensal bacteria in innate immunity and the epithelial barrier." Infect Immun 68(5): 2907-15.

Krisanaprakornkit, S., A. Weinberg, et al. (1998). "Expression of the peptide antibiotic human beta-defensin 1 in cultured gingival epithelial cells and gingival tissue." Infect Immun 66(9): 4222-8.

Lehrer, R. I. and T. Ganz (2002). "Defensins of vertebrate animals." Curr Opin Immunol 14(1): 96-102.

Lehrer, R. I., A. K. Lichtenstein, et al. (1993). "Defensins: antimicrobial and cytotoxic peptides of mammalian cells." Annu Rev Immunol 11: 105-28.

Loos, B. G., R. P. John, et al. (2005). "Identification of genetic risk factors for periodontitis and possible mechanisms of action." J Clin Periodontol 32 Suppl 6: 159-79.

Lourbakos, A., J. Potempa, et al. (2001). "Arginine-specific protease from Porphyromonas gingivalis activates protease-activated receptors on human oral epithelial cells and induces interleukin-6 secretion." Infect Immun 69(8): 5121-30.

Lu, Q., L. Jin, et al. (2004). "Expression of human beta-defensins-1 and -2 peptides in unresolved chronic periodontitis." J Periodontal Res 39(4): 221-7.

Lu, Q., L. P. Samaranayake, et al. (2005). "Expression of human beta-defensin-3 in gingival epithelia." J Periodontal Res 40(6): 474-81.

Luch, A. (2005). "Nature and nurture - lessons from chemical carcinogenesis." Nat Rev Cancer 5(2): 113-25.

Maestre, J. R., A. Bascones, et al. (2007). "Odontogenic bacteria in periodontal disease and resistance patterns to common antibiotics used as treatment and prophylaxis in odontology in Spain." Rev Esp Quimioter 20(1): 61-7.

Magert, H. J., K. Drogemuller, et al. (2005). "Serine proteinase inhibitors in the skin: role in homeostasis and disease." Curr Protein Pept Sci 6(3): 241-54. 
Maisetta, G., G. Batoni, et al. (2003). "Activity of human beta-defensin 3 alone or combined with other antimicrobial agents against oral bacteria." Antimicrob Agents Chemother 47(10): 3349-51.

Manuyakorn, A., R. Paulus, et al. (2010). "Cellular histone modification patterns predict prognosis and treatment response in resectable pancreatic adenocarcinoma: results from RTOG 9704." J Clin Oncol 28(8): 1358-65.

McKay, M. S., E. Olson, et al. (1999). "Immunomagnetic recovery of human neutrophil defensins from the human gingival crevice." Oral Microbiol Immunol 14(3): 190-3.

McMichael, J. W., A. I. Maxwell, et al. (2005). "Antimicrobial activity of murine lung cells against Staphylococcus aureus is increased in vitro and in vivo after elafin gene transfer." Infect Immun 73(6): 3609-17.

Meyer-Hoffert, U., N. Wichmann, et al. (2003). "Supernatants of Pseudomonas aeruginosa induce the Pseudomonas-specific antibiotic elafin in human keratinocytes." Exp Dermatol 12(4): 418-25.

Michalowicz, B. S., D. Aeppli, et al. (1991). "Periodontal findings in adult twins." J Periodontol 62(5): 293-9.

Michalowicz, B. S., S. R. Diehl, et al. (2000). "Evidence of a substantial genetic basis for risk of adult periodontitis." J Periodontol 71(11): 1699-707.

Minami, M. (1999). "The levels of secretory leukocyte protease inhibitor and alpha 1protease inhibitor in gingival crevicular fluid from adult periodontal patients." J Jpn Soc Periodontol 41: 28-35.

Mitsuishi, K., T. Nakamura, et al. (2005). "The squamous cell carcinoma antigens as relevant biomarkers of atopic dermatitis." Clin Exp Allergy 35(10): 1327-33.

Miyasaki, K. T., A. L. Bodeau, et al. (1990). "In vitro sensitivity of oral, gram-negative, facultative bacteria to the bactericidal activity of human neutrophil defensins." Infect Immun 58(12): 3934-40.

Molhuizen, H. O. and J. Schalkwijk (1995). "Structural, biochemical, and cell biological aspects of the serine proteinase inhibitor SKALP/elafin/ESI." Biol Chem Hoppe Seyler 376(1): 1-7.

Murakami, M., T. Ohtake, et al. (2002). "Cathelicidin antimicrobial peptides are expressed in salivary glands and saliva." J Dent Res 81(12): 845-50.

Nathan, C. (2006). "Neutrophils and immunity: challenges and opportunities." Nat Rev Immunol 6(3): 173-82.

Nussbaum, G. and L. Shapira (2011). "How has neutrophil research improved our understanding of periodontal pathogenesis?" J Clin Periodontol 38 Suppl 11: 49-59.

O'Brien-Simpson, N. M., P. D. Veith, et al. (2004). "Antigens of bacteria associated with periodontitis." Periodontol 2000 35: 101-34.

Oelke, K. and B. Richardson (2004). "Decreased T cell ERK pathway signaling may contribute to the development of lupus through effects on DNA methylation and gene expression." Int Rev Immunol 23(3-4): 315-31.

Offenbacher, S., S. P. Barros, et al. (2008). "Rethinking periodontal inflammation." J Periodontol 79(8 Suppl): 1577-84.

Offenbacher, S., V. Katz, et al. (1996). "Periodontal infection as a possible risk factor for preterm low birth weight." J Periodontol 67(10 Suppl): 1103-13.

Ouellette, A. J. (1999). "Paneth cell antimicrobial peptides and the biology of the mucosal barrier." American Journal of Physiology 277: G257-261. 
Ouhara, K., H. Komatsuzawa, et al. (2005). "Susceptibilities of periodontopathogenic and cariogenic bacteria to antibacterial peptides, \{beta\}-defensins and LL37, produced by human epithelial cells." J Antimicrob Chemother 55(6): 888-96.

Payne, J. B., L. M. Golub, et al. (2011). "The effect of subantimicrobial-dose-doxycycline periodontal therapy on serum biomarkers of systemic inflammation: a randomized, double-masked, placebo-controlled clinical trial." J Am Dent Assoc 142(3): 262-73.

Peleg, S., F. Sananbenesi, et al. (2010). "Altered histone acetylation is associated with agedependent memory impairment in mice." Science 328(5979): 753-756.

Persson, G. R. and R. E. Persson (2008). "Cardiovascular disease and periodontitis: an update on the associations and risk." J Clin Periodontol 35(8 Suppl): 362-79.

Peters, B. M., M. E. Shirtliff, et al. (2010). "Antimicrobial peptides: primeval molecules or future drugs?" PLoS Pathog 6(10): e1001067.

Pfundt, R., F. van Ruissen, et al. (1996). "Constitutive and inducible expression of SKALP/elafin provides anti-elastase defense in human epithelia." J Clin Invest 98(6): 1389-99.

Potempa, J., A. Banbula, et al. (2000). "Role of bacterial proteinases in matrix destruction and modulation of host responses." Periodontol 2000 24: 153-92.

Potempa, J., R. Pike, et al. (1995). "The multiple forms of trypsin-like activity present in various strains of Porphyromonas gingivalis are due to the presence of either Arggingipain or Lys-gingipain." Infect Immun 63(4): 1176-82.

Potempa, J. and J. Travis (1996). "Porphyromonas gingivalis proteinases in periodontitis, a review." Acta Biochim Pol 43(3): 455-65.

Premratanachai, P., S. Joly, et al. (2004). "Expression and regulation of novel human betadefensins in gingival keratinocytes." Oral Microbiol Immunol 19(2): 111-7.

Puklo, M., A. Guentsch, et al. (2008). "Analysis of neutrophil-derived antimicrobial peptides in gingival crevicular fluid suggests importance of cathelicidin LL-37 in the innate immune response against periodontogenic bacteria." Oral Microbiol Immunol 23(4): 328-35.

Putsep, K., G. Carlsson, et al. (2002). "Deficiency of antibacterial peptides in patients with morbus Kostmann: an observation study." Lancet 360(9340): 1144-9.

Raj, P. A., K. J. Antonyraj, et al. (2000). "Large-scale synthesis and functional elements for the antimicrobial activity of defensins." Biochem J 347 Pt 3: 633-41.

Richardson, B. (2003). "DNA methylation and autoimmune disease." Clin Immunol 109(1): 72-9.

Rickard, A. H., P. Gilbert, et al. (2003). "Bacterial coaggregation: an integral process in the development of multi-species biofilms." Trends Microbiol 11(2): 94-100.

Rock, F. L., G. Hardiman, J.C. Timans, R.A. Kastelein, J.F. Bazan (1998). "A family of human receptors structurally related to Drosophila Toll." Proc Natl Acad Sci U S A 95: 588593.

Rodenhiser, D. and M. Mann (2006). "Epigenetics and human disease: translating basic biology into clinical applications." CMAJ 174(3): 341-8.

Sahasrabudhe, K. S., J.R. Kimball, T. Morton, W. Weinberg, B.A. Dale (2000). "Expression of the antimicrobial peptide, human b-defensin 1, in duct cells of minor salivary glands and detection in saliva." Journal of Dental Research 79: 1669-1674. 
Sallenave, J. M., G. A. Cunningham, et al. (2003). "Regulation of pulmonary and systemic bacterial lipopolysaccharide responses in transgenic mice expressing human elafin." Infect Immun 71(7): 3766-74.

Schenkein, H. A. (2002). "Finding genetic risk factors for periodontal diseases: is the climb worth the view?" Periodontol 2000 30: 79-90.

Schroeder, B. O., Z. Wu, et al. (2011). "Reduction of disulphide bonds unmasks potent antimicrobial activity of human beta-defensin 1." Nature 469(7330): 419-23.

Schulze-Luehrmann, J. and S. Ghosh (2006). "Antigen-receptor signaling to nuclear factor kappa B." Immunity 25(5): 701-15.

Selsted, M. E. and A. J. Ouellette (2005). "Mammalian defensins in the antimicrobial immune response." Nat Immunol 6(6): 551-7.

Selsted, M. E., S.I. Miller, A.H. Henschen, A.J. Ouellette (1992). "Enteric defensins: antibiotic peptide components of intestinal host defense." Journal of Cell Biology 118: 929936.

Shin, J. E., Y. S. Kim, et al. (2010). "Treponema denticola suppresses expression of human \{beta\}-defensin-3 in gingival epithelial cells through inhibition of the toll-like receptor 2 axis." Infect Immun 78(2): 672-9.

Silverman, G. A., P. I. Bird, et al. (2001). "The serpins are an expanding superfamily of structurally similar but functionally diverse proteins. Evolution, mechanism of inhibition, novel functions, and a revised nomenclature." J Biol Chem 276(36): 33293-6.

Simpson, A. J., A. I. Maxwell, et al. (1999). "Elafin (elastase-specific inhibitor) has antimicrobial activity against gram-positive and gram-negative respiratory pathogens." FEBS Lett 452(3): 309-13.

Socransky, S. S. and A. Haffajee (2003). Microbiology of periodontal disease. Clin Periodontol Implant Dent. J. Lindhe. Oxford, Blackwell.

Socransky, S. S. and A. D. Haffajee (1992). "The bacterial etiology of destructive periodontal disease: current concepts." J Periodontol 63(4 Suppl): 322-31.

Socransky, S. S. and A. D. Haffajee (2003). Microbiology of periodontal disease. Clin Periodontol Implant Dent. J. Lindhe. Oxford, Blackwell. 4.

Socransky, S. S. and A. D. Haffajee (2005). "Periodontal microbial ecology." Periodontol 2000 38: 135-87.

Socransky, S. S., A. D. Haffajee, et al. (1998). "Microbial complexes in subgingival plaque." J Clin Periodontol 25(2): 134-44.

Socransky, S. S., C. Smith, et al. (2002). "Subgingival microbial profiles in refractory periodontal disease." J Clin Periodontol 29(3): 260-8.

Som, A., S. Vemparala, et al. (2008). "Synthetic mimics of antimicrobial peptides." Biopolymers 90(2): 83-93.

Strahl, B. D. and C. D. Allis (2000). "The language of covalent histone modifications." Nature 403(6765): 41-5.

$\mathrm{Su}$, X., D. M. Lucas, et al. (2009). "Validation of an LC-MS based approach for profiling histones in chronic lymphocytic leukemia." Proteomics 9(5): 1197-206.

Sugawara, S., A. Uehara, et al. (2001). "Neutrophil proteinase 3-mediated induction of bioactive IL-18 secretion by human oral epithelial cells." J Immunol 167(11): 656875 . 
Sutherland, J. E. and M. Costa (2003). "Epigenetics and the environment." Ann N Y Acad Sci 983: 151-60.

Svotelis, A., N. Gevry, et al. (2010). "H2A.Z overexpression promotes cellular proliferation of breast cancer cells." Cell Cycle 9(2): 364-70.

Tao, R., R. J. Jurevic, et al. (2005). "Salivary antimicrobial peptide expression and dental caries experience in children." Antimicrob Agents Chemother 49(9): 3883-8.

Tew, G. N., D. Clements, et al. (2006). "Antimicrobial activity of an abiotic host defense peptide mimic." Biochim Biophys Acta 1758(9): 1387-92.

Tew, G. N., D. Liu, et al. (2002). "De novo design of biomimetic antimicrobial polymers." Proc Natl Acad Sci U S A 99(8): 5110-4.

Tonetti, M. S., M. A. Imboden, et al. (1994). "Localized expression of mRNA for phagocytespecific chemotactic cytokines in human periodontal infections." Infect Immun 62(9): 4005-14.

Tonetti, M. S., M. A. Imboden, et al. (1998). "Neutrophil migration into the gingival sulcus is associated with transepithelial gradients of interleukin-8 and ICAM-1." J Periodontol 69(10): 1139-47.

Turkoglu, O., G. Emingil, et al. (2009). "Gingival crevicular fluid levels of cathelicidin LL-37 and interleukin-18 in patients with chronic periodontitis." J Periodontol 80(6): 96976.

Turkoglu, O., G. Kandiloglu, et al. (2011). "Antimicrobial peptide hCAP-18/LL-37 protein and mRNA expressions in different periodontal diseases." Oral Dis 17(1): 60-7.

Tuter, G., B. Kurtis, et al. (2007). "Effects of scaling and root planing and sub-antimicrobial dose doxycycline on oral and systemic biomarkers of disease in patients with both chronic periodontitis and coronary artery disease." J Clin Periodontol 34(8): 673-81.

Uehara, A., K. Muramoto, et al. (2003). "Neutrophil serine proteinases activate human nonepithelial cells to produce inflammatory cytokines through protease-activated receptor 2." J Immunol 170(11): 5690-6.

Valore, E. V., C. H. Park, et al. (1998). "Human beta-defensin-1: an antimicrobial peptide of urogenital tissues." J Clin Invest 101(8): 1633-42.

van der Reijden, W. A., C. J. Bosch-Tijhof, et al. (2006). "prtH in Tannerella forsythensis is not associated with periodontitis." J Periodontol 77(4): 586-90.

van Wetering, S., P. J. Sterk, et al. (1999). "Defensins: key players or bystanders in infection, injury, and repair in the lung?" J Allergy Clin Immunol 104(6): 1131-8.

van Wetering, S., A. C. van der Linden, et al. (2000). "Regulation of SLPI and elafin release from bronchial epithelial cells by neutrophil defensins." Am J Physiol Lung Cell Mol Physiol 278(1): L51-8.

van Winkelhoff, A. J., D. Herrera Gonzales, et al. (2000). "Antimicrobial resistance in the subgingival microflora in patients with adult periodontitis. A comparison between The Netherlands and Spain." J Clin Periodontol 27(2): 79-86.

Vardar-Sengul, S., T. Demirci, et al. (2007). "Human beta defensin-1 and -2 expression in the gingiva of patients with specific periodontal diseases." J Periodontal Res 42(5): 42937.

Veith, P. D., Y. Y. Chen, et al. (2004). "Porphyromonas gingivalis RgpA and Kgp proteinases and adhesins are $\mathrm{C}$ terminally processed by the carboxypeptidase CPG70." Infect Immun 72(6): 3655-7. 
Williams, S. E., T. I. Brown, et al. (2006). "SLPI and elafin: one glove, many fingers." Clin Sci (Lond) 110(1): 21-35.

Wilmes, M., B. P. Cammue, et al. (2011). "Antibiotic activities of host defense peptides: more to it than lipid bilayer perturbation." Natural Product Reports May 27 E-published ahead of print.

Wilson, C. L., A. J. Ouellette, et al. (1999). "Regulation of intestinal alpha-defensin activation by the metalloproteinase matrilysin in innate host defense." Science 286(5437): 1137.

Yin, L. and W. O. Chung (2011). "Epigenetic regulation of human beta-defensin 2 and CC chemokine ligand 20 expression in gingival epithelial cells in response to oral bacteria." Mucosal Immunol 4(4): 409-19.

Yin, L. and B. A. Dale (2007). "Activation of protective responses in oral epithelial cells by Fusobacterium nucleatum and human beta-defensin-2." J Med Microbiol 56(Pt 7): 976-87.

Yin, L., B. Swanson, et al. (2010). "Differential effects of periopathogens on host protease inhibitors SLPI, elafin, SCCA1, and SCCA2." Journal of Oral Microbiology Epub May 4.

Ying, Q. L. and S. R. Simon (1993). "Kinetics of the inhibition of human leukocyte elastase by elafin, a 6-kilodalton elastase-specific inhibitor from human skin." Biochemistry 32(7): 1866-74.

Yuyama, N., D. E. Davies, et al. (2002). "Analysis of novel disease-related genes in bronchial asthma." Cytokine 19(6): 287-96.

Zaiou, M., V. Nizet, et al. (2003). "Antimicrobial and protease inhibitory functions of the human cathelicidin (hCAP18/LL-37) prosequence." J Invest Dermatol 120(5): 810-6.

Zanetti, M., R. Gennaro, et al. (2000). "Structure and biology of cathelicidins." Adv Exp Med Biol 479: 203-18.

Zani, M. L., S. M. Nobar, et al. (2004). "Kinetics of the inhibition of neutrophil proteinases by recombinant elafin and pre-elafin (trappin-2) expressed in Pichia pastoris." Eur J Biochem 271(12): 2370-8.

Zasloff, M. (2002). "Antimicrobial peptides of multicellular organisms." Nature 415(6870): 389-95.

Zhao, C., I. Wang, et al. (1996). "Widespread expression of beta-defensin hBD-1 in human secretory glands and epithelial cells." FEBS Lett 396(2-3): 319-22.

Zhong, D., M. Yang, et al. (1998). "[In vitro sensitivity of oral gram-negative bacteria to the bactericidal activity of defensins]." Hua Xi Kou Qiang Yi Xue Za Zhi 16(1): 26-8. 


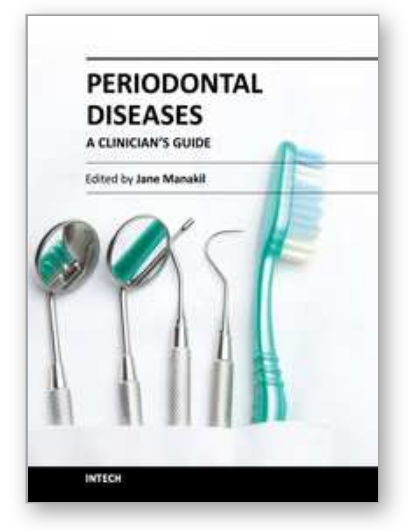

\author{
Periodontal Diseases - A Clinician's Guide \\ Edited by Dr. Jane Manakil
}

ISBN 978-953-307-818-2

Hard cover, 368 pages

Publisher InTech

Published online 03, February, 2012

Published in print edition February, 2012

"Periodontal diseases" is a web-based resource intended to reach the contemporary practitioners as well as educators and students in the field of periodontology. It is fully searchable and designed to enhance the learning experience. Within the book a description is presented of the current concepts presenting the complex interactions of microbial fingerprint, multiple genotypes, and host modulations. In addition, an overview is given of the clinical outcome of the disease's progression, as influenced by the epigenetic factors. Emerging concepts on periodontitis as a risk factor for various systemic diseases and as a bilateral modulating factor have been elucidated in detail as well.

\title{
How to reference
}

In order to correctly reference this scholarly work, feel free to copy and paste the following:

Whasun Oh Chung and Jonathan Y. An (2012). Periodontal Disease and Gingival Innate Immunity - Who Has the Upper Hand?, Periodontal Diseases - A Clinician's Guide, Dr. Jane Manakil (Ed.), ISBN: 978-953-307-8182, InTech, Available from: http://www.intechopen.com/books/periodontal-diseases-a-clinician-sguide/periodontal-disease-and-gingival-innate-immunity-who-has-the-upper-hand-

\section{INTECH}

open science | open minds

\section{InTech Europe}

University Campus STeP Ri Slavka Krautzeka 83/A 51000 Rijeka, Croatia Phone: +385 (51) 770447

Fax: +385 (51) 686166 www.intechopen.com

\section{InTech China}

Unit 405, Office Block, Hotel Equatorial Shanghai No.65, Yan An Road (West), Shanghai, 200040, China 中国上海市延安西路65号上海国际贵都大饭店办公楼405单元 Phone: +86-21-62489820

Fax: $+86-21-62489821$ 
(C) 2012 The Author(s). Licensee IntechOpen. This is an open access article distributed under the terms of the Creative Commons Attribution 3.0 License, which permits unrestricted use, distribution, and reproduction in any medium, provided the original work is properly cited. 